\title{
Quantification of Tackiness of a Grease: The Road to a Method
}

\author{
Emmanuel P. Georgiou ${ }^{1, *}$, Dirk Drees ${ }^{1}$, Michel De Bilde ${ }^{1}$, Michael Anderson ${ }^{2}$, Matthias Carlstedt ${ }^{3}$ \\ and Olaf Mollenhauer ${ }^{3}$ \\ $1 \quad$ Falex Tribology NV, Wingepark 23B, 3110 Rotselaar, Belgium; ddrees@falex.eu (D.D.); \\ mdebilde@falex.eu (M.D.B.) \\ 2 Falex Corporation, 1020 Airpark Drive, Sugar Grove, IL 60554, USA; manderson@falex.com \\ 3 Kompass Gmbh, Ehrenbergstraße 11, 98693 Ilmenau, Germany; m.carlstedt@kompass-sensor.com (M.C.); \\ o.mollenhauer@kompass-sensor.com (O.M.) \\ * Correspondence: egeorgiou@falex.eu; Tel.: +32-164-079-65
}

check for

updates

Citation: Georgiou, E.P.; Drees, D.; De Bilde, M.; Anderson, M.; Carlstedt, M.; Mollenhauer, O. Quantification of Tackiness of a Grease: The Road to a Method. Lubricants 2021, 9, 32. https://doi.org/10.3390/lubricants 9030032

Received: 2 December 2020

Accepted: 5 March 2021

Published: 7 March 2021

Publisher's Note: MDPI stays neutral with regard to jurisdictional claims in published maps and institutional affiliations.

Copyright: (c) 2021 by the authors. Licensee MDPI, Basel, Switzerland. This article is an open access article distributed under the terms and conditions of the Creative Commons Attribution (CC BY) license (https:/ / creativecommons.org/licenses/by/ $4.0 /)$.

\begin{abstract}
In this work, we report on the most recent progress in studying temperature influence on tackiness of greases, as well as the reproducibility of the method. Tackiness and adhesion of greases have been identified as key intrinsic properties that can influence their functionality and performance. During the last eight years, a reliable method to quantify the tackiness and adhesion of greases has evolved from an experimental lab-scale set-up towards a standardised approach, including an ASTM method and a dedicated test tool. The performance of lubricating greases-extensively used in diverse industrial applications-is strongly dependent on their adherence to the substrate, cohesion and thread formation or tackiness of the greases. This issue attracts more and more industrial interest as the complexity in grease formulation evolves and it is harder to differentiate between available greases. With this method, grease formulators will have an efficient measurement tool to support their work.
\end{abstract}

Keywords: grease; tackiness; adhesion

\section{Introduction}

Tackiness was first identified as an intrinsic characteristic of adhesives materials in the 1940s [1]. Based on this fundamental work, tackiness was defined as the resistance needed to separate two solid surfaces joined by an adhesive layer in its liquid state [1]. In the following years, the term tackiness was adopted in different industrial fields, including that of grease manufacturing. However, depending on the industrial application, it is interpreted in a different way. For example, in the elastomer industry, it is considered as the work required to remove a material from a polymeric film/material [2,3], whereas in the grease industry, tackiness is viewed as the ability of a grease to form threads as it is being pulled apart [3].

Up to now, the most widely used method to evaluate thread formation (tackiness) of greases is the finger test [3]. Based on this empirical method, a grease film is applied between the thumb and index finger, and then they are pulled apart, resulting in the formation of grease threads (Figure 1). According to this test, the longer the threads are, the higher the tackiness of the grease is. The finger test might be a simple-to-perform and zero-cost method, but it is also very empirical and subjective since the results are strongly dependent on the user who is performing the test. Indeed, depending on the amount of grease used and the retraction speed, a different result can be obtained. Another field test that is also used to assess the tackiness of greases is the hammer test [4]. In this method, a 5-pound hammer head is dropped onto a small quantity of grease applied on an anvil. The distance to which the grease is thrown or spreads determines its tackiness (a higher distance means higher tackiness). This method also has the disadvantage that it is not well controlled and that it measures the consistency of the grease upon impact and provides less information about the adhesion or tackiness. In addition, the sensitivity of this approach is 
rather poor, especially when comparing similar greases. For this reason, there is a strong need to develop a consistent, repeatable method that can quantify tackiness.

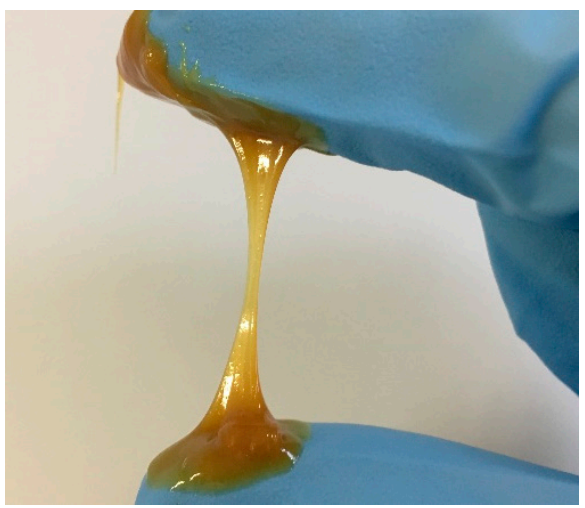

Figure 1. Thread formation during physical separation of a grease.

During the last 10 years, more sophisticated experimental methods with different testers have been developed [5-10]. In all cases, the theoretical principle is based on measuring the interaction forces between a probe and a grease layer. From the obtained know-how, the authors have developed a dedicated tester that measures adhesion, separation energy and thread formation (tackiness) of greases from indentation-retraction curves. According to this method, a fixed grease volume is applied on a standardised steel holder. An indenter is gradually brought into contact with the grease until a preset contact load (maximum force in Figure 2). Then, the indenter is gradually moved away from the greased substrate under well-controlled conditions until there is complete physical separation. The pull-off force is identified as the force required to start the physical separation of the indenter from the grease (indicated by the minimum force in Figure 1). As the indenter is retracted, a grease thread forms (Figure 2), which resembles the finger test (Figure 1). The thread length is defined as the displacement from the start of the separation until the force is zero (thread is broken). In addition, the separation energy (Se) is defined as the energy needed to fully separate the indenter from the grease by the pull-off force and is calculated from integration of the area between the start-up of the retraction motion (minimum force) and complete physical separation (Figure 2). Based on this method, tackier greases form longer threads, as with the finger test, whereas the pull-off force relates to the adhesion (also known as stickiness). There is a common misconception that the pull-off force (adhesion) is also an indication of tackiness (thread formation). However, this is not the case, as proved by recent research publications $[11,12]$.

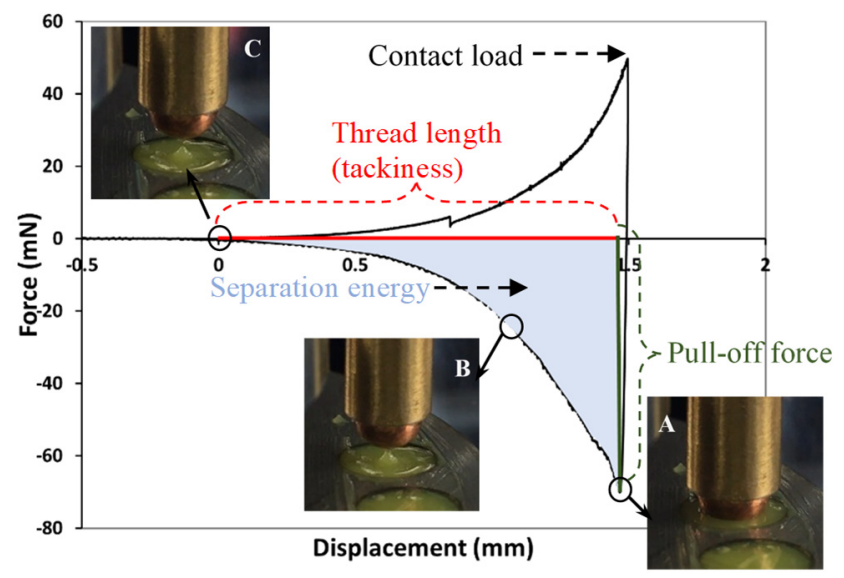

Figure 2. An indicative indentation-retraction curve and measured values. 
Despite the significant progress that has been made to quantify grease tackiness, several aspects still need to be addressed. For example, it is known that the performance of greases is temperature dependent. This means that their intrinsic properties, including adhesion, cohesion and tackiness (thread formation), should be also influenced by the temperature in which they operate. Up to now, all tackiness test protocols have been performed at room temperature. Thus, in this work, an attempt is made to investigate the effect of temperature on the adhesion, cohesion, and tackiness of industrial greases. This is gaining importance as new greases are formulated for high-temperature applications like in automotive, aeronautics and metal forming [13]. Furthermore, the repeatability and reproducibility of this method are discussed, as they are key criteria for the systematic development and ranking of greases. Finally, in this work, a first attempt is made to investigate the influence of grease degradation due to wear on its adhesion and ability to form threads.

\section{Materials and Methods}

The adhesion and tackiness of greases were measured with a Falex Tackiness Adhesion Analyser (TAA) tester (Figure $3 \mathrm{a}$ ). As counter-material, a $3 \mathrm{~mm} \varnothing$ copper ball was used (Figure 3b). The selection of a point contact and a copper ball is based on the authors' previous experience [9], where they observed better repeatability of measurements with this combination. The reason is that point contacts create well-defined individual strings, whereas copper is a relatively inert metal. Different contact geometries (e.g., flat-on-flat) and material combinations can also be used. For this method, a specialised 316 stainless steel holder with a surface roughness (Sa) of $\leq 0.4 \mu \mathrm{m}$ (ISO 25178) was developed. This holder consists of 15 individual grease scoops (Figure 3c). Each grease scoop was filled in carefully with approximately $1 \mathrm{~mL}$ of grease and then carefully spread with a spatula, forming a homogenous flat surface (Figure 3c). The 15 scoops can be then used to perform 15 different indentation-retraction test profiles with variable conditions (e.g., retraction speeds, contact load and temperatures).

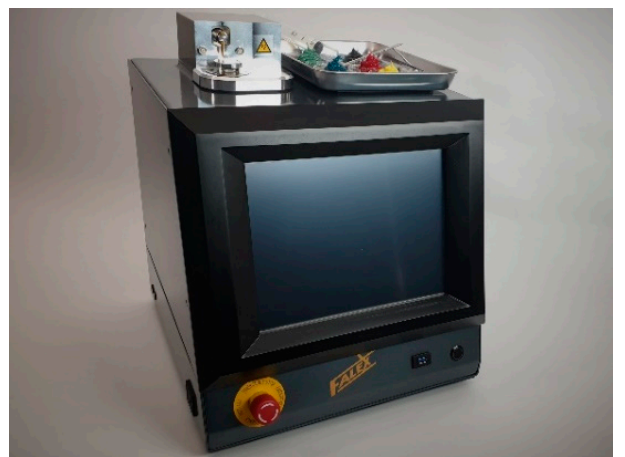

(a)

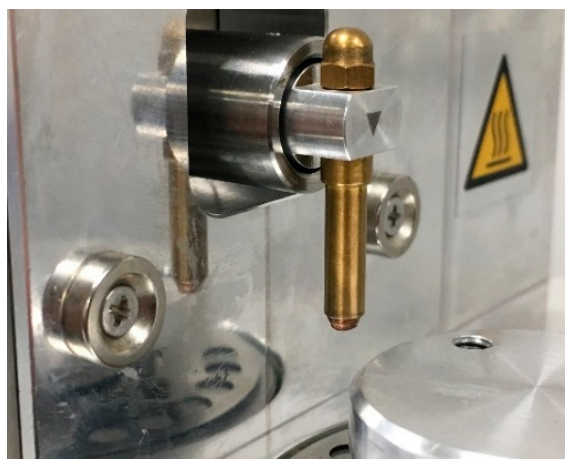

(b)



(c)

Figure 3. (a) Tackiness Adhesion Analyser (TAA), (b) $\mathrm{mN}$ load sensor with $3 \mathrm{~mm} \varnothing \mathrm{Cu}$ ball attached to it and (c) grease scoop holder with 15 individual pots (positions). 
A 15-step profile was programmed to perform indentation-retraction measurements under 5 different retraction speeds and 3 temperatures in one automatic run. The complete profile is given in Table 1. Ten repeats (cycles) were performed per condition for the same grease to get information about the repeatability of the method and to perform statistical analysis of the obtained data.

Table 1. Indentation-retraction test profile.

\begin{tabular}{ccccc}
\hline Step & $\begin{array}{c}\text { Retraction } \\
\text { Speed }(\mathbf{m m} / \mathbf{s})\end{array}$ & $\begin{array}{c}\text { Temperature } \\
\left({ }^{\circ} \mathbf{C}\right)\end{array}$ & $\begin{array}{c}\text { Retraction } \\
\text { Distance }(\mathbf{m m})\end{array}$ & $\begin{array}{c}\text { Repeats } \\
\text { (Cycles) }\end{array}$ \\
\hline 1 & 0.1 & 30 & 10 & 10 \\
2 & 0.5 & 30 & 10 & 10 \\
3 & 1 & 30 & 10 & 10 \\
4 & 2 & 30 & 10 & 10 \\
5 & 5 & 30 & 10 & 10 \\
6 & 0.1 & 60 & 10 & 10 \\
7 & 0.5 & 60 & 10 & 10 \\
8 & 1 & 60 & 10 & 10 \\
9 & 2 & 60 & 10 & 10 \\
10 & 5 & 60 & 10 & 10 \\
11 & 0.1 & 90 & 10 & 10 \\
12 & 0.5 & 90 & 10 & 10 \\
13 & 1 & 90 & 10 & 10 \\
14 & 2 & 90 & 10 & 10 \\
15 & 5 & 90 & 10 & \\
\hline
\end{tabular}

During each indentation-retraction measurement (cycle), the force on the load sensor was measured as a function of the displacement of the indenter, and the absolute values of the pull-off force, thread length and separation energy (as explained in Figure 2) were extracted and analysed with an Excel macro software and with OriginLab ${ }^{\circledR}$ OriginPro 9 software.

In this work, 8 fully formulated commercially available greases were tested. A description of these greases is given in Table 2. However, due to confidentiality, their names and compositions are not included.

Table 2. Overview of greases used in this work.

\begin{tabular}{|c|c|c|c|}
\hline Grease & NLGI Grade & Thickener & Base Oil \\
\hline A & 2 & Lithium complex & $\begin{array}{c}\text { ISO VG } 220 \text { (kinematic viscosity } \\
\text { of } 220 \mathrm{cSt} \text { at } 40^{\circ} \mathrm{C} \text { ) }\end{array}$ \\
\hline B & 2 & Lithium & $\begin{array}{l}\text { Mineral base (kinematic viscosity } \\
\text { of } 220 \mathrm{cSt} \text { at } 40^{\circ} \mathrm{C}\end{array}$ \\
\hline C & $1-2$ & Complex calcium sulphonate & $\begin{array}{c}\text { Synthetic (PAO) mineral } \\
\text { (kinematic viscosity of } 80 \mathrm{cSt} \text { at } \\
\left.40^{\circ} \mathrm{C}\right)\end{array}$ \\
\hline $\mathrm{D}$ & 00 & Paratac & $\begin{array}{l}\text { Paraffinic base oil (kinematic } \\
\text { viscosity of } 90 \mathrm{cSt} \text { at } 40^{\circ} \mathrm{C} \text { ) }\end{array}$ \\
\hline $\mathrm{E}$ & 2 & Lithium complex & $\begin{array}{c}\text { Mineral base (kinematic viscosity } \\
\text { of } 150 \mathrm{cSt} \text { at } 40^{\circ} \mathrm{C}\end{array}$ \\
\hline $\mathrm{F}$ & 2 & Polymer-modified lithium & $\begin{array}{c}\text { Mineral base (kinematic viscosity } \\
\text { of } 115 \mathrm{cSt} \text { at } 40^{\circ} \mathrm{C}\end{array}$ \\
\hline G & 2 & Polymer-modified lithium & $\begin{array}{c}\text { Mineral base (kinematic viscosity } \\
\text { of } 115 \mathrm{cSt} \text { at } 40^{\circ} \mathrm{C}\end{array}$ \\
\hline $\mathrm{H}$ & 2 & Calcium & $\begin{array}{l}\text { mineral base (kinematic viscosity } \\
\text { of } 115 \mathrm{cSt} \text { at } 40^{\circ} \mathrm{C}\end{array}$ \\
\hline
\end{tabular}




\section{Results and Discussion}

\subsection{Effect of Temperature}

The performance of greases is strongly dependent on the contact conditions/geometry and the environment under which they operate [9]. This method can perform multiple measurements of adhesion and tackiness under varying conditions automatically so that the speed, load and temperature can be recorded with one run. Based on the authors' previous experience [6-12], an optimised test profile is proposed, as presented in Table 1. In this profile, the speed and temperature vary, whereas the load remains constant. The reason for not changing the load, too, is that for the selected contact geometry (point contact) and load range, the adhesion and tackiness appear to be less prone to load variations. Up to now, the majority of research work on adhesion and tackiness has focused mainly on contact conditions and less on the temperature effect, which is a proven factor influencing the performance and lifetime of greases [14-18]. Indeed, as can be seen in Figure 4, for the selected greases and temperature range, the increase in temperature leads to an increase in both adhesion (pull-off force) and tackiness (thread formation). However, depending on the formulation of the grease a different behaviour can be monitored. For example, the pull-off force of grease A significantly increases when increasing the temperature from 30 to $90{ }^{\circ} \mathrm{C}$ (Figure $4 \mathrm{a}$ ). This indicates that the grease attaches more firmly onto the steel substrate (bottom of the grease scoop). In addition, this increase appears to be more gradual for grease A (Figure 4a) than for greases B (Figure 4c) and C (Figure 4e), where a sharp rise increases at $90^{\circ} \mathrm{C}$. A similar behaviour in terms of adhesion is observed for greases B and C. It is also very interesting that the same temperature dependence is observed for both retraction speeds, namely 0.1 and $1 \mathrm{~mm} / \mathrm{s}$, which is an indication that this behaviour is temperature related. Indeed, the viscous and viscoelastic responses of greases are significantly influenced by temperature changes [19-21]. In addition, phase transitions within the microstructure of the grease can also influence its yield strength [22] and force required for the deformation and separation of this layer.

When evaluating the tackiness (thread formation) of greases A, B and C (Figure 4b,d,f), a different temperature effect is observed between them, as, for example, grease $C$ seems to be less temperature dependent (for the selected range) than greases A and B. Furthermore, it should be pointed out that adhesion (pull-off force) is a different grease characteristic than tackiness (thread length). For instance, when comparing greases A and C, grease A has a higher pull-off force than $C$ but forms shorter threads. To put it in simple terms, grease $\mathrm{A}$ is stickier than grease $\mathrm{C}$, yet grease $\mathrm{C}$ is tackier than grease $\mathrm{A}$.

To illustrate that adhesion and tackiness are two different intrinsic properties of greases, a comparative test was designed and performed. In particular, a duplicate test was performed for the same grease, counter-material and test conditions, but in the second run, anti-stick paper was fixed to the bottom of the grease scoop, as shown in Figure 5a. The interesting outcome of these tests is that the thread formation (tackiness) is not affected by the use of anti-stick paper (Figure 5b), but on the contrary, the pull-off force (stickiness) drops significantly (Figure 5c). This clearly indicates that adhesion and tackiness should be considered separately. 


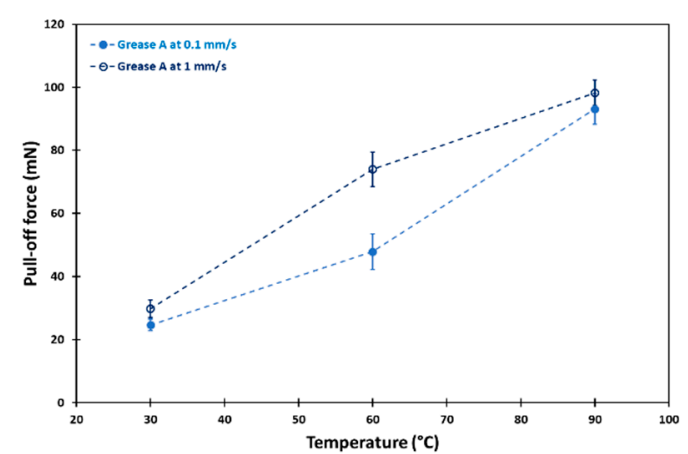

(a)

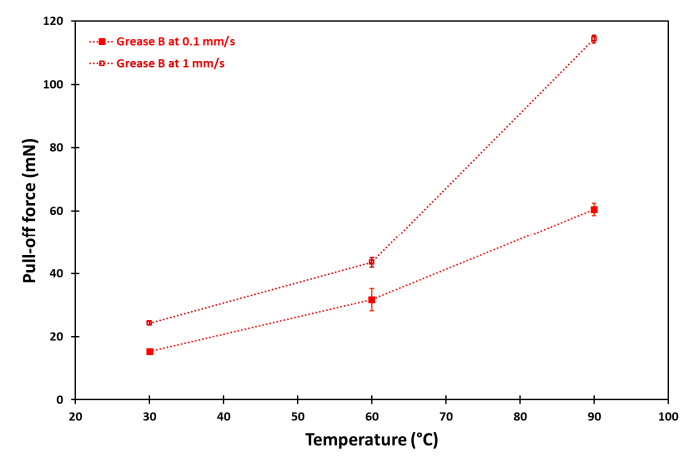

(c)



(e)



(b)



(d)

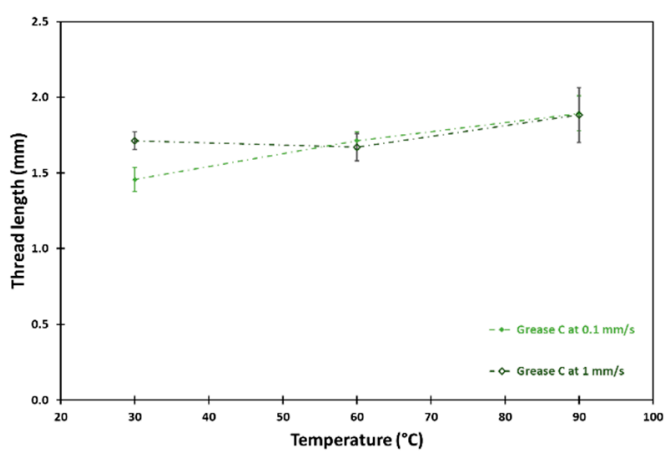

(f)

Figure 4. Effect of temperature and retraction on the pull-off force and thread formation of greases $(\mathbf{a}, \mathbf{b})$ A, (c,d) B and $(\mathbf{e}, \mathbf{f})$ C. 


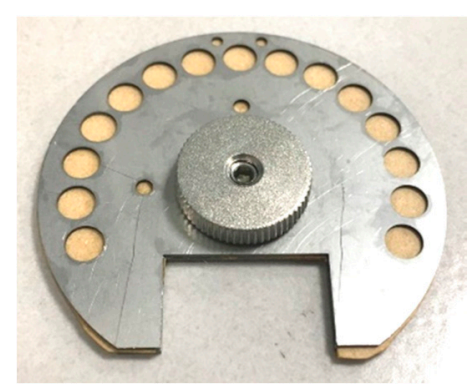

(a)

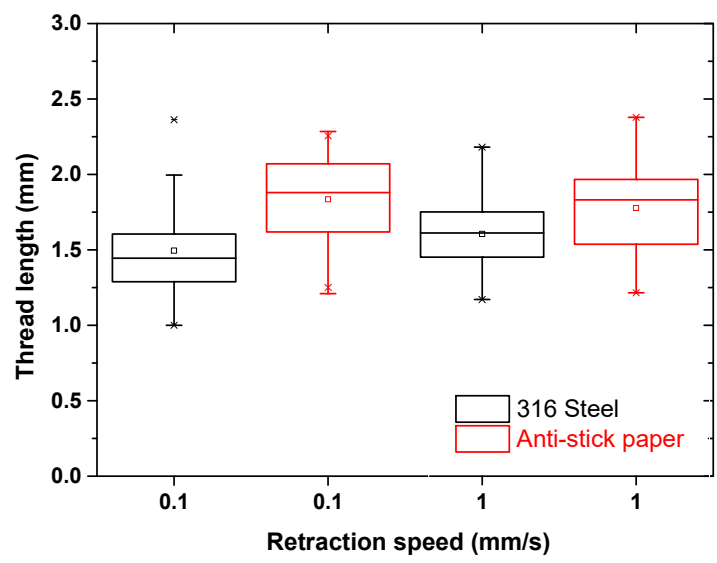

(b)

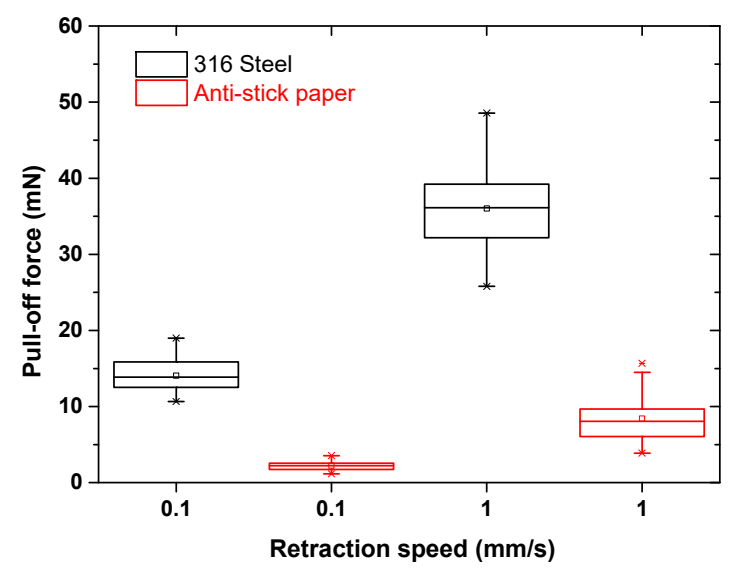

(c)

Figure 5. (a) Grease scoop with anti-stick paper. Effect of anti-stick paper on the (b) thread formation (tackiness) and (c) pull-off force (adhesion) of grease D for 0.1 and $1 \mathrm{~mm} / \mathrm{s}$ retraction speed at $30{ }^{\circ} \mathrm{C}$.

\subsection{Repeatability and Reproducibility of Method}

A significant step towards the standardisation of this method is to evaluate its repeatability and reproducibility. To achieve this, firstly the influence of the test apparatus was evaluated by testing the same grease by the same user and under the same test conditions with nine different TAA modules (see Figure 6). Results in terms of pull-off force and thread length were similar between the nine modules, as the fluctuation within one test group is in the range of $8-16 \%$ for the pull-off force and $4-12 \%$ for the thread length and between the different modules around $8 \%$ and $7 \%$, respectively, at $0.1 \mathrm{~mm} / \mathrm{s}$. When increasing the retraction speed, the fluctuation between the individual test groups can rise up to $25 \%$ (depending on the grease). In particular, for the same grease, when the retraction speed is $1 \mathrm{~mm} / \mathrm{s}$, the fluctuation within one test group is in the range of 4-25\% for the pull-off force and $6-12 \%$ for the thread length and between the different modules is around $16 \%$ and $11 \%$, respectively. 


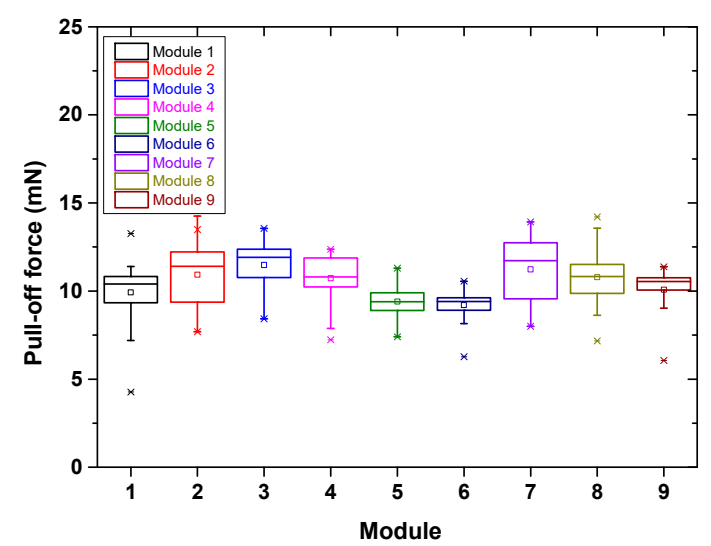

(a)

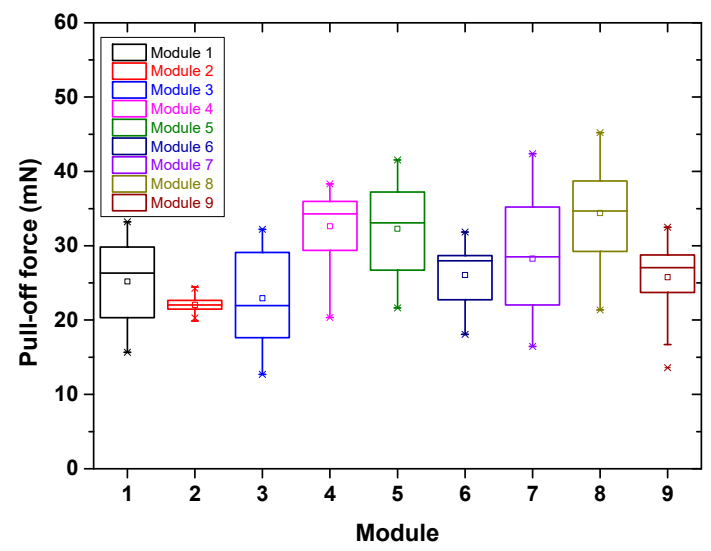

(c)



(b)

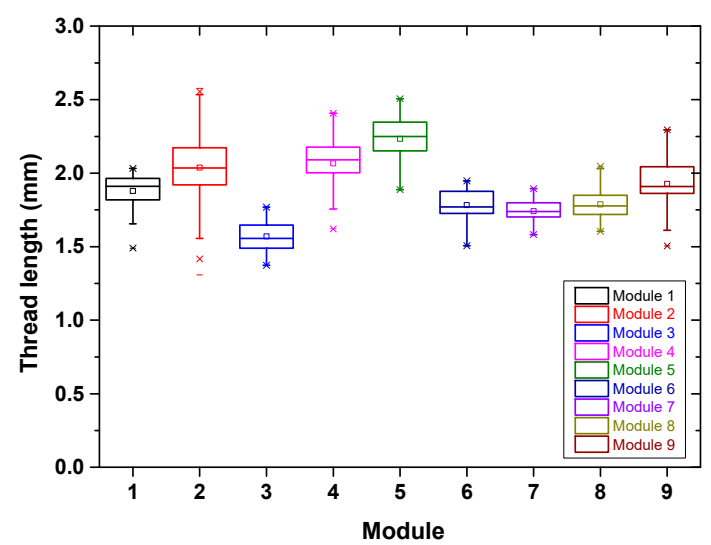

(d)

Figure 6. Comparison of 9 different modules for grease E. (a) Pull-off force and (b) thread length for $0.1 \mathrm{~mm} / \mathrm{s} \mathrm{retraction}$ speed at $30{ }^{\circ} \mathrm{C}$. (c) Pull-off force and (d) thread length for $1 \mathrm{~mm} / \mathrm{s}$ retraction speed at $30{ }^{\circ} \mathrm{C}$.

What is also very interesting is that the repeatability of other greases, under lower speed retraction conditions $(0.1 \mathrm{~mm} / \mathrm{s})$, is also in the range of $8-16 \%$ for the pull-off force and $5-12 \%$ for the thread length for each module (Figure 7). Again, the fluctuation between groups is similar to the variability between the different modules, which is around $8 \%$ for the pull-off force and $7 \%$ for the thread length.

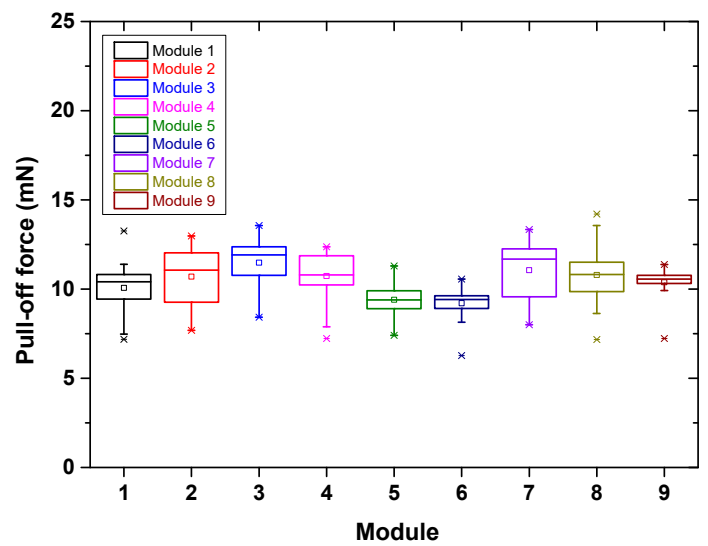

(a)

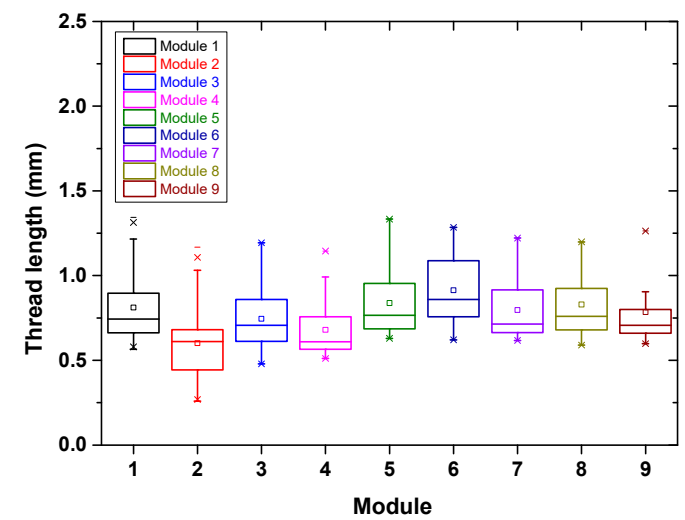

(b)

Figure 7. Comparison of 9 different modules for grease F. (a) Pull-off force and (b) thread length for $0.1 \mathrm{~mm} / \mathrm{s}$ retraction speed at $30{ }^{\circ} \mathrm{C}$. 
As a second step, a comparison between users was performed for the same grease, module and test conditions, as presented in Figure 8. The fluctuation between the five users at $0.1 \mathrm{~mm} / \mathrm{s}$ is $7-12 \%$ for the pull-off force and $5-13 \%$ for the thread length. These values fall again within the fluctuation observed in each measurement group (one user, one module and one grease), which is approximately $8 \%$ for the pull-off force and $6 \%$ for the thread length at $0.1 \mathrm{~mm} / \mathrm{s}$ speed.

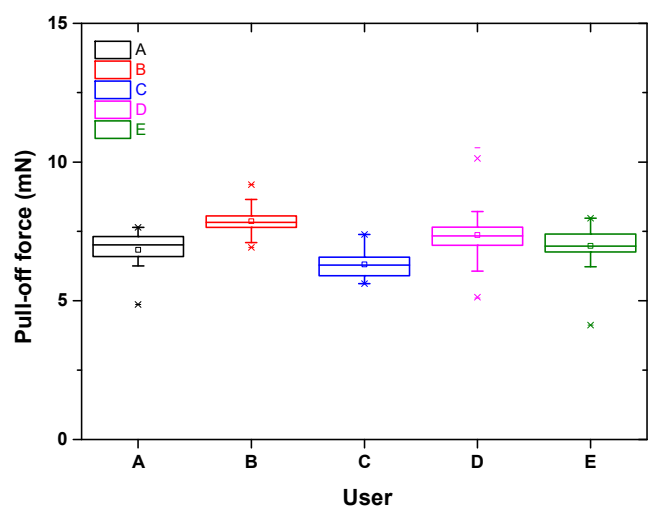

(a)

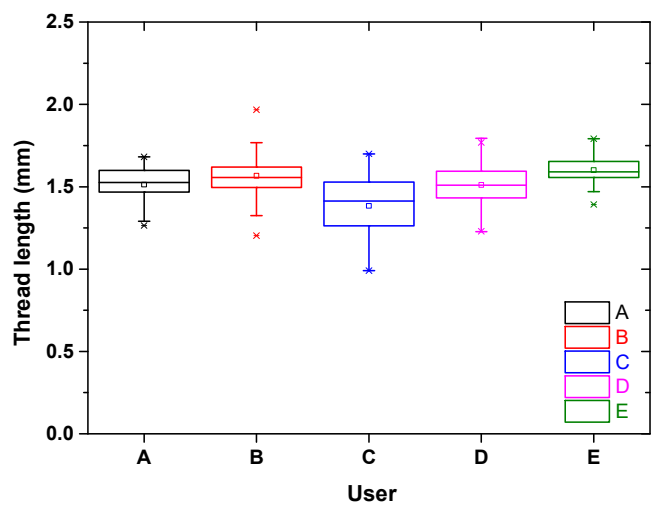

(b)

Figure 8. Comparison of (a) pull-off force and (b) thread length between 5 different users for the same modules for grease G. Test conditions: $0.1 \mathrm{~mm} / \mathrm{s}$ retraction speed at $30^{\circ} \mathrm{C}$.

It should be pointed out that the reproducibility of grease measurements with other standard methods like ASTM 2509 Timken tests is $73 \%$ and $X^{*}$ sqrt(average) for ASTM D4170 Fretting tests. Thus, the authors believe that the developed protocol is quite repeatable and in line with other standardised methods and that the observed fluctuations are mainly due to the heterogeneous and complex nature of greases [23].

\subsection{Other Possibilities: Grease Monitoring}

One of the potential applications of this method is to use it to easily monitor changes in the behaviour of a grease. Since only a small quantity of grease is needed per test, it can be used to evaluate changes in the adhesion and tackiness of greases in the field, as, for example, in a wind turbine. Thus, it can be potentially used to monitor changes in the structure of a grease. For instance, the effect of wear on the adhesion and tackiness of a grease can be seen in Figures 9 and 10. Indeed, the more severe the wear conditions (point contacts in four-ball vs. line contact for Timken tests) and the smaller the quantity of the grease used ( $15 \mathrm{~g}$ four-ball vs. $5 \mathrm{~kg}$ for Timken tests), the more significant the effect of wear degradation on the pull-off force and thread length.

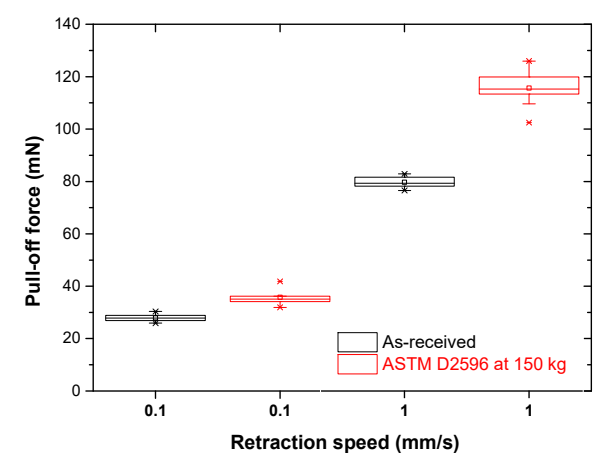

(a)

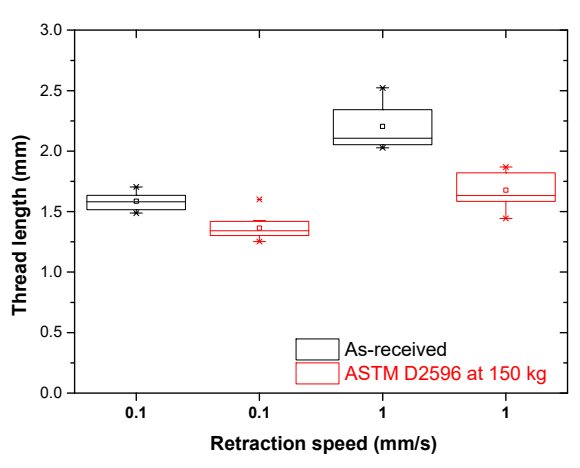

(b)

Figure 9. Effect of 4-ball wear testing (ASTM D2596) on the (a) pull-off force (adhesion) and (b) thread length (tackiness) of grease $\mathrm{H}$. 




(a)

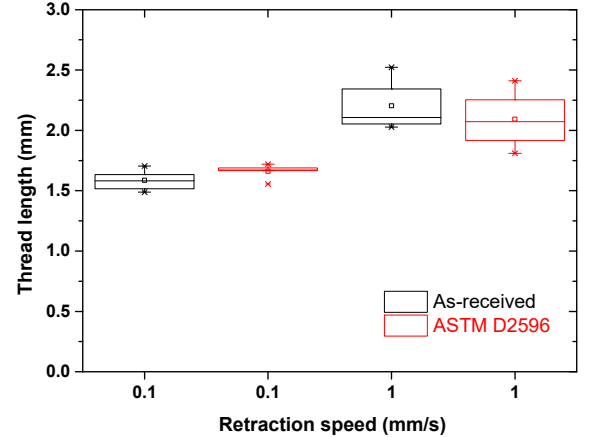

(b)

Figure 10. Effect of Timken testing (ASTM D2509) on the (a) pull-off force (adhesion) and (b) thread length (tackiness) of grease $\mathrm{H}$.

\section{Conclusions}

In this work, the most recent progress on measuring the adhesion and tackiness of greases with the indentation-retraction approach is presented. In particular, the ability of a grease to adhere to a surface (pull-off force) and to form threads when it is being pulled apart (tackiness) strongly depend on the temperature. However, the influence of temperature is not the same for these two grease characteristics. In addition, it was proved that adhesion is strongly dependent on the holder, which means that this property is system oriented. On the other hand, thread formation does not seem to be influenced; thus, it is more of an intrinsic characteristic of the grease. As a follow-up, the influence of other environmental factors such as humidity and material composition will be investigated.

For this method to move towards standardisation, its repeatability and reproducibility should be addressed. From an internal round robin exercise, it was found that the repeatability of the method for one group of measurements (one module, one tester and one grease) is in the range of $5-15 \%$. A similar fluctuation was found between the different modules for the same grease and user, as well as between different users for the same grease and module. From the authors' point of view, this indicates that the method is quite repeatable and reproducible and that the fluctuation is possibly due to the heterogeneous and complex grease structure. However, to draw safe conclusions, a more extended round robin is underway between different labs and well-defined and formulated greases. Another possibility of this method, apart from grease formulation and development, can also be grease condition monitoring.

Author Contributions: Tester development, O.M. and M.C.; testing, E.P.G., D.D. and M.D.B.; data analysis, E.P.G., D.D. and M.A.; writing, E.P.G. and D.D.; review, M.A. All authors have read and agreed to the published version of the manuscript.

Funding: This research received no external funding.

Institutional Review Board Statement: Not applicable.

Informed Consent Statement: Not applicable.

Data Availability Statement: Not applicable.

Conflicts of Interest: The authors declare no conflict of interest.

\section{References}

1. Bikerman, J.J. The fundamentals of tackiness and adhesion. J. Colloid Sci. 1946, 2, 163-175. [CrossRef]

2. Barquins, M.; Maugis, D. Tackiness of elastomers. J. Adhes. 1981, 13, 53-65. [CrossRef]

3. Gay, C.; Leibler, L. Theory of tackiness. Phys. Rev. Lett. 1998, 82, 936-939. [CrossRef]

4. Moon, M. On the right tack. Lubes' $n^{\prime}$ Greases 2018, 24, 64-69.

5. Morway, A.J.; Young, D.W. Grease Compositions. U.S. Patent 2,491,055, 13 December 1949. 
6. Achanta, S.; Jungk, M.; Drees, D. Characterisation of cohesion, adhesion, and tackiness of lubricating greases using approachretraction experiments. Tribol. Int. 2011, 44, 1127-1133. [CrossRef]

7. Georgiou, E.P.; Drees, D.; De Bilde, M. The quantitive method for measuring grease tackiness. Lube Mag. 2016, 132, 18-19.

8. Georgiou, E.P.; Drees, D.; De Bilde, M.; Anderson, M. Can we put a value on the adhesion and tackiness of greases? Tribol. Lett. 2018, 66, 60. [CrossRef]

9. Georgiou, E.P.; Drees, D.; De Bilde, M.; Anderson, M. Quantitative approach to measuring the adhesion and tackiness of industrial greases. Tribol. Und Schmier. 2019, 66, 37-43.

10. Harmon, M.; Powell, B.; Barlebo-Larsen, I.; Lewis, R. Development of a grease tackiness test. Tribol. Trans. 2019, 62, 207-217. [CrossRef]

11. Georgiou, E.P.; Drees, D.; De Bilde, M.; Anderson, M. How reliable and sensitive is the new Indentation/Retraction method in measuring tackiness of industrial greases? In Proceedings of the 74th STLE Annual Meeting and Exhibition, Nashville, TN, USA, 19-23 May 2019.

12. Georgiou, E.P.; Drees, D.; De Bilde, M.; Feltman, F.; Anderson, M. Grease Adhesion and Tackiness: Do They Influence Friction? NLGI Spokesm. 2020, 84, 20-25.

13. Mang, T. Encyclopedia of Lubricants and Lubrication; Springer: Berlin, Germany, 2014.

14. Pan, J.; Cheng, Y.; Vacca, A.; Yang, J. Effect of temperature on grease flow properties in pipes. Tribol. Trans. 2016, 59, 569-578. [CrossRef]

15. Wang, H.; Li, Y.; Zhang, G.; Wang, J. Effect of temperature on rheological properties of lithium-based magnetorheological grease. Smart Mater. Struct. 2019, 28, 035002. [CrossRef]

16. Hurley, S.; Cann, P.M.; Spikes, H.A. Thermal degradation of greases and the effect on lubrication performance. Tribol. Ser. 1998, 34, 75-83.

17. Lugt, P.M. Modern advancements in lubricating grease technology. Tribol. Int. 2016, 97, 467-477. [CrossRef]

18. Booser, E.R.; Khonsari, M.M. Grease life in ball bearings: The effect of temperatures. Tribol. Lubr. Technol. 2010, 66, 36-44.

19. Williamson, B.P.; Walters, K.; Bates, T.W.; Coy, R.C.; Milton, A.L. The viscoelastic properties of multigrade oils and their effect of journal-bearing characteristics. J. Non-Newton. Fluidmech. 1997, 73, 115-126. [CrossRef]

20. Delgado, M.A.; Valencia, C.; Sanchez, M.C.; Franco, J.M.; Callegos, C. Thermorheological behaviour of a lithium lubricating grease. Tribol. Lett. 2006, 23, 47-53. [CrossRef]

21. Delgado, M.A.; Valencia, C.; Sanchez, M.C.; Franco, J.M.; Callegos, C. Influence of soap concentration and oil viscosity on the rheology and microstructure of lubricating greases. Ind. Eng. Chem. Res. 2006, 45, 1902-1910. [CrossRef]

22. Cyriac, F.; Lugt, P.M.; Bosman, R. On a new method to determine the yield stress in lubricating grease. Tribol. Trans. 2015, 58, 1021-1030. [CrossRef]

23. Lugt, P.M.; Velickov, S.; Tripp, J.H. On the chaotic behavior of grease lubrication in rolling bearings. Tribol. Trans. 2009, 52, 581-590. [CrossRef] 